BRIEG LECOUBLET ${ }^{1,2,3,4}$

E-mail: brieg.lecoublet@gmail.com

YVAN PETIT, Ph.D. $2,3,4$

E-mail: yvan.petit@etsmtl.ca

ERIC WAGNAC, Ph.D. ${ }^{2,3,4}$

E-mail: eric.wagnac@etsmtl.ca

DOMINIC BOISCLAIR ${ }^{1,2}$

E-mail: dominicboisclair@hotmail.com

PIERRE-JEAN ARNOUX, Ph.D. ${ }^{1,2}$

E-mail: pierre-jean.arnoux@univ-eiffel.fr

${ }^{1}$ Aix Marseille Université, Université Gustave Eiffel, LBA

Boulevard Pierre Dramard, 13015 Marseille, France

2 iLab-Spine - Laboratoire international en imagerie

et biomécanique du Rachis

5400 Boulevard Gouin O, Montréal,

QC H4J 1C5, Canada

${ }^{3}$ Department of Mechanical Engineering

École de technologie supérieure

1100 Rue Notre-Dame Ouest, Montréal,

QC H3C 1K3, Canada

${ }^{4}$ Research Center, Sacré-Cœur Hospital Montreal

5400 Boul Gouin O, Montréal, QC H4J 1C5, Canada
Safety and Security in Traffic Original Scientific Paper

Submitted: 31 Aug. 2020

Accepted: 12 Jan. 2021

\title{
NECK BRACES AND DRIVING POSTURE AFFECT NECK MOBILITY ON POWERED TWO-WHEELERS
}

\section{ABSTRACT}

Cervical spine injuries are a major concern for motorcyclists in traffic accidents and racing competitions. Neck braces aim to prevent cervical spine injuries during accidents by reducing the neck range of motion, and keeping it under physiological limits. This work aims to evaluate the ability of neck braces to reduce neck mobility for two driving postures associated with PTW configurations. The neck mobility of twelve volunteer subjects testing four neck braces on two powered two-wheelers (scooter and racing motorbike) is measured using an optoelectronic motion capture system. With the tested neck braces worn, neck mobility is significantly reduced as compared to the physiological range of motion in all degrees of freedom. However, only flexion/extension is reduced by all neck braces tested. This suggests that these brace designs do not provide protection against all the cervical spine loading directions that may occur in a trauma. Furthermore, specific type of each powered two-wheeler considered significantly affects the neck mobility in axial rotation, as well as the postero-anterior and caudo-cranial translations, thus underscoring the need to consider the driving posture when evaluating neck brace devices.

\section{KEYWORDS}

motorcyclist; powered two-wheeler; neck brace; cervical spine; neck mobility; driving posture.

\section{INTRODUCTION}

Motorcyclists are generally highly vulnerable drivers, who are largely exposed to fatal injuries. In 2017, 6,129 [1] and 89,000 [2] motorcyclists were respectively injured in France and in the USA. Moreover, $10 \%$ of motorcycle accidents are associated with spinal injuries [3]. A significant proportion of Powered Two-Wheeler (PTW) accidents involve cervical spine injuries, which can lead to serious long-term motor deficiencies, and produce the highest rates $(27 \%)$ of neurological deficiencies for motorcyclists [4]. Furthermore, $53 \%$ of spine injuries leading to patient death involve the cervical spine [3]. Spine injuries cost approximately 750 million dollars annually in North America [5]. Cervical spine injuries are directly related to multi-directional mechanical loading involved during trauma [6-10]. Among motorcyclists, these injuries are mainly caused by a direct impact on the helmeted head during an accident [11], leading to combined rotational movements greater than the physiological ranges of motion of the cervical spine. Several methods based on different measuring devices [12-18] are used to study the physiological mobility of the human head and neck in rotation in an attempt to assess the 
vulnerability of the cervical spine. Since the neck is capable of complex motions, its range of motion cannot be fully characterized by rotational movements alone. In order to measure the neck range of motion (ROM), including rotational and translational movements, a method based on an optoelectronic motion capture system [19] is used in this work.

Neck braces were introduced over ten years ago to protect motorcyclists from cervical spine injuries [20], and are available in two different types: active and passive. Active neck braces, such as airbag devices, involve an activation system that is triggered during impact. Passive neck braces, on the other hand, have no triggering mechanisms, and are positioned on the shoulders and thorax of the motorcyclist. This work focuses on passive neck braces, and more specifically, on one semi-rigid (Ortema) and three rigid devices (EVS, Alpinestar, and KTM). These devices are designed to reduce the vulnerability of the cervical spine by reducing the range of motion of the head/neck, and keeping it under physiological limits; they also distribute the impact energy on the shoulders [20]. The performance of these devices was recently investigated in $[21,22]$. These studies showed uncertainties regarding their protection effectiveness, thus confirming the need to develop a normalized evaluation procedure for such devices.

Originally, neck braces were designed only for racing motorbikes, but today, they are used for every type of PTW (scooter, road motorbike, enduro, trial, etc.). However, each type of PTW involves a specific driving posture, which may also affect the neck ROM. Some studies have investigated the effect of the motorcyclist riding posture and anthropometric characteristics on physical fatigue and postural discomfort [23-27], but none have analyzed the effect of the driving posture on neck mobility. This work focuses on two typical driving postures (adopted on a scooter and on a racing motorbike). It aims to evaluate, in quasi-static loading conditions, the capacity of neck braces to reduce neck mobility and keep it under its physiological range of motion, depending on the driving postures associated with each PTW type.

\section{MATERIALS AND METHODS}

\subsection{Subjects, neck braces, and powered two-wheelers}

Twelve subjects aged between 21 and 51 years $(27.3 \pm 4.7$ years old), weighing $74.1 \pm 11.6 \mathrm{~kg}$ and measuring $1.78 \pm 0.07 \mathrm{~m}$ were recruited for this study. Ethics approval was obtained by the Aix-Marseille University ethics committee. Subjects whose medical history (surgery, trauma, injury, and pathology) included events related to the cervical spine were excluded from this study.

Four neck braces were tested (Figure 1): (A) Alpinestar-Bionic neck supports CF, (B) EVS-RC Evolution, (C) KTM-Neck brace ADV II, and (D) Ortema neck brace. EVS, Alpinestar, and KTM are rigid, while Ortema is semi-rigid. EVS and KTM are made of carbon fiber, fiberglass reinforced polyamide, polyurethane, and polycarbonate. The Alpinestar neck brace is made of polycarbonate for the main support, and a thick polyester foam is maintained on the structure with Velcro tape. Ortema is made of polyurethane foam and carbon fiber, and is attached to the thorax with a strap. These four neck braces use the shoulders, the upper back, and the thorax as supports.

All tests were performed on a scooter (SYM Joyride; $125 \mathrm{cc}$ ) and on a race motorcycle (ZXR 750 Kawasaki) in order to investigate the potential effect of the specific postures associated with each PTW type. Both PTWs (Figure 2) were modified for the purpose of this experiment. A back support was

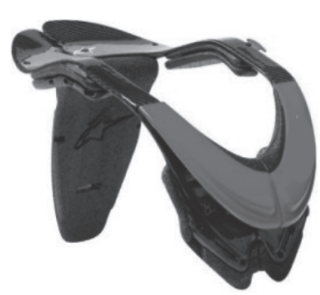

A

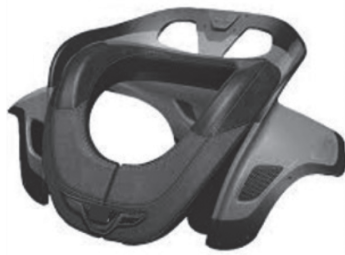

B

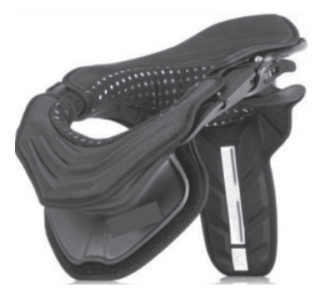

C

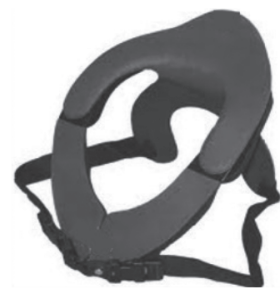

$\mathrm{D}$

Figure 1 - Four neck braces tested during experiments: (A) Alpinestar-Bionic neck supports CF, (B) EVS-RC Evolution, (C) KTM-brace ADV II, and (D) Ortema neck brace 


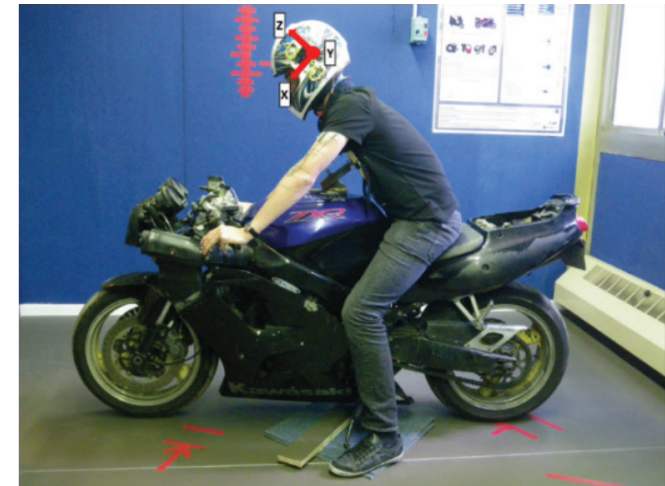

a) ZXR 750 Kawasaki

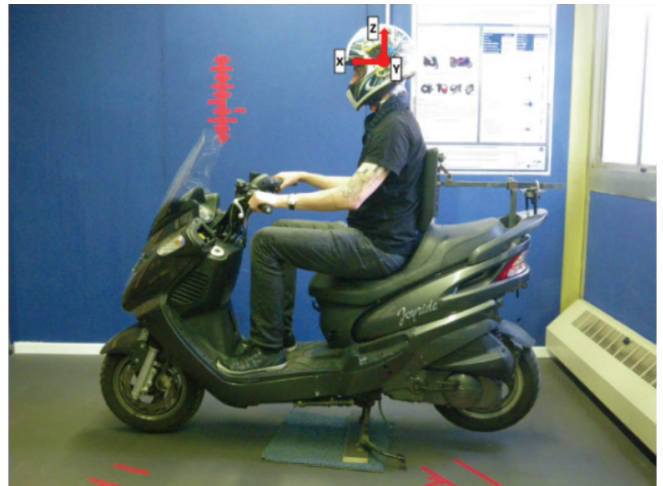

b) SYM Joyride $125 \mathrm{cc}$

Figure 2 - Two Powered Two-Wheelers tested with volunteer subjects during experiments

added on the scooter, and a thorax support on the race motorbike, to ensure reproducible positioning of the trunk and to focus solely on the neck mobility.

\subsection{Data acquisition}

This study measured the neck ROM as a combination of rotational and linear displacements in healthy volunteers using an optoelectronic motion capture system (Codamotion, Charnwood Dynamics Ltd.). The 3D coordinates of six optoelectronic markers placed on the helmet (SHARK, S800, size L) were measured to calculate the subject's neck ROM. The rotational neck movement was computed from the rotation matrix calculated from the initial and final positions of the markers resulting from the movement. The translational neck movement along three axes ( $\mathrm{X}$-axis aligned toward the subject's anterior direction, Y-axis aligned toward the subject's left side, and $Z$-axis aligned toward the cranial direction) were computed from the initial and final positions of a virtual marker (labeled $\mathrm{C}$ in Figure 3) corresponding to the head centroid [19]. The details of this method and its evaluation were reported in a recent work [19]. Data acquisition was performed at a frequency of $100 \mathrm{~Hz}$ (per marker). The RMS amplitude of the noise was less than 0.1 $\mathrm{mm}$ in the $\mathrm{X}$ - and Z-axes and less than $0.3 \mathrm{~mm}$ in the Y-axis. The latency of the motion capture system was between 5 and 10 milliseconds.

\subsection{Experiments}

Each volunteer had to first adopt a neutral initial position by lying on the support added to the PTW, with their eyes pointing on a marker placed on the wall, representing the horizon. A preliminary session was done without recording, allowing time for the subject to get familiar with the testing environment. The subject then performed a first session
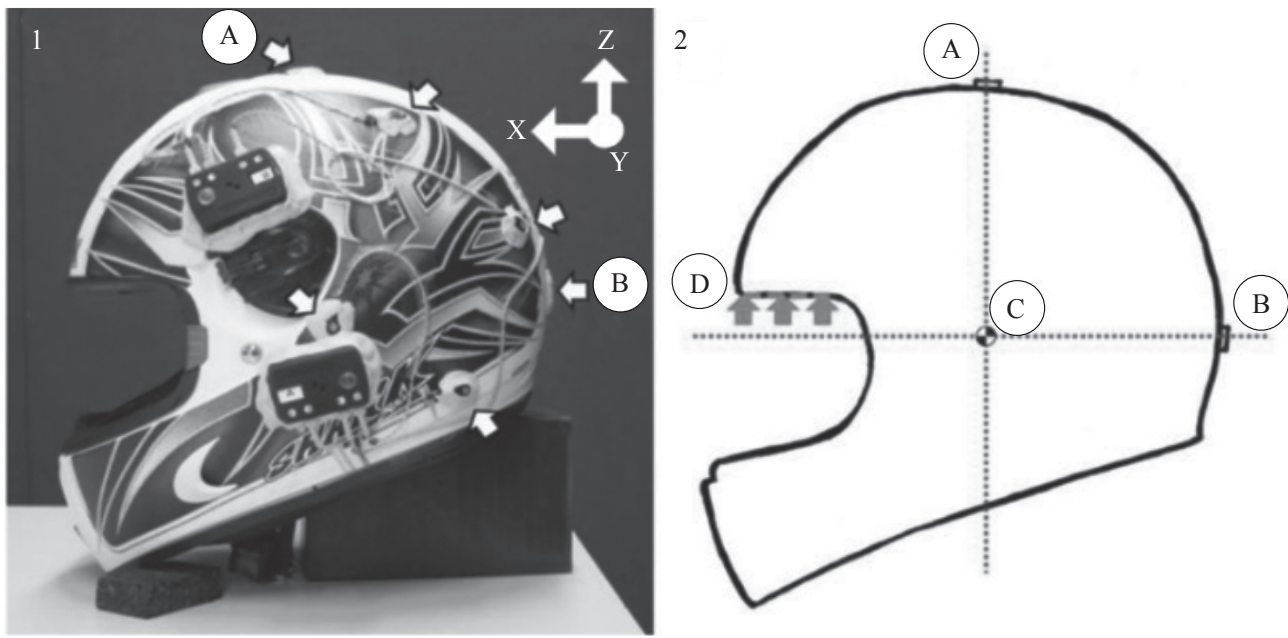

A - top marker, B - rear end marker, C - virtual marker, D - superior flat surface of the eye port

Figure 3 -Shark helmet used by subjects with optoelectronic markers for the Codamotion system .2 


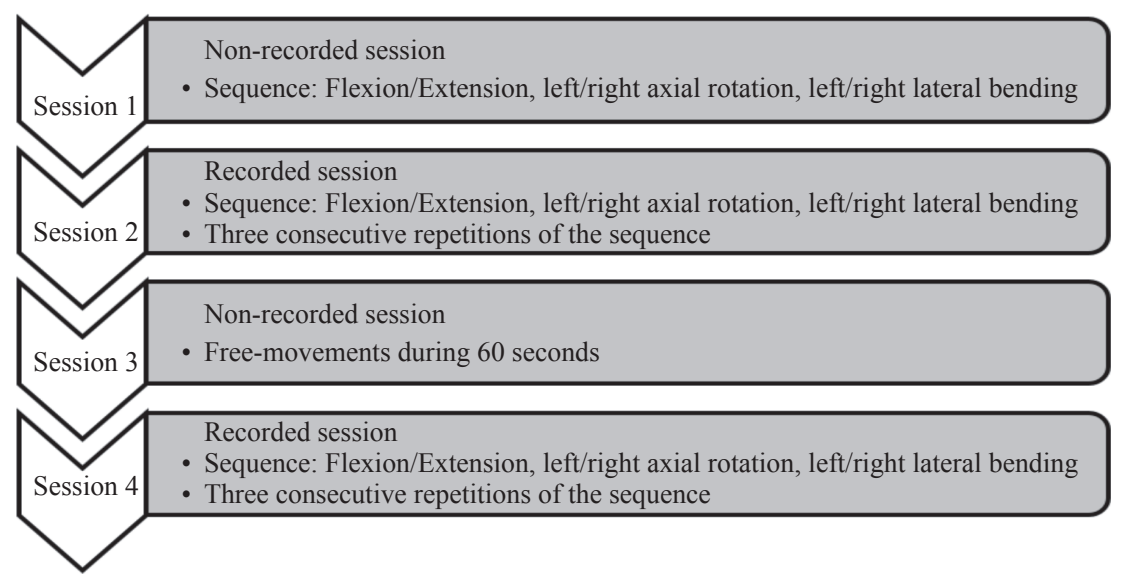

Figure 4-Complete test protocol for neck ROM measurements for each volunteer subject (12) with each set of testing conditions (10), for a total of 120 tests

of head movements without recording: flexion/extension, left/right axial rotation, and left/right lateral bending. A second session was recorded with the same movement sequence performed three consecutive times. The subject did a third session with free movements for 60 seconds, without recording. Finally, a fourth session exactly reproducing the second session was recorded (Figure 4).

Ten conditions were tested in random order between the subjects: wearing (A) Alpinestar, (B) EVS, (C) KTM, and (D) Ortema, or without any neck braces (S), and adopting two postures (scooter (S) and racing motorbike (Y)). For each testing condition, the testing sequence described (Figure 4) was used. A total of 120 complete testing sequences were performed (12 volunteer subjects and 10 different testing conditions). With 3 consecutive movement sequences during recording sessions 2 and 4 , a total of $720(120 \times 6)$ datasets were acquired. An average value of 6 acquisitions per testing conditions was calculated. For each session, ROM were calculated for the following six movements: axial rotation, right and left lateral bending, flexion/extension, and translations in the $\mathrm{X}, \mathrm{Y}$, and $\mathrm{Z}$ directions. This analysis was performed in a coordinate system defined for each session.

Non-parametric statistical analyses were used since the assumption of normal distribution was rejected, as confirmed by a Shapiro-Wilk normality test. A first analysis was performed using a Wilcoxon matched Pair test to highlight potential significant differences in neck ROM (rotational and translational), depending on the driving posture. Furthermore, another statistical analysis was conducted using a Mann-Whitney test to identify potential significant differences in neck mobility between the configuration with and without the four neck braces. The significance level (p-value) was set to 0.05 for both statistical analyses.

\section{RESULTS}

\subsection{Rotational range of motion}

For the axial rotational movement, the physiological range of motion of the neck (without neck brace) was found significantly higher $(\mathrm{p}=0.008)$ on the scooter driving posture $\left(153 \pm 20^{\circ}\right)$ than for the racing motorbike $\left(135 \pm 21^{\circ}\right)$ (Table 1). The EVS neck

Table 1 - Neck mobility for rotation and translation without neck brace on the scooter and on the racing motorbike Wilcoxon matched Pairs test

\begin{tabular}{||l|c|c|c||}
\hline & $\begin{array}{c}\text { SS } \\
\text { Average (SD) }\end{array}$ & $\begin{array}{c}\text { YS } \\
\text { Average (SD) }\end{array}$ & $\begin{array}{c}\text { Wilcoxon } \\
\text { p-value }\end{array}$ \\
\hline \hline Axial rotation $\left[{ }^{\circ}\right]$ & $153(20)$ & $135(21)$ & $0.008^{*}$ \\
\hline${\text { Lateral bending }\left[{ }^{\circ}\right]}$ & $94(16.0)$ & $101(30)$ & 0.308 \\
\hline Flexion-extension $\left.{ }^{\circ}\right]$ & $117(13)$ & $115(19)$ & 0.530 \\
\hline $\mathrm{X}$ translation $[\mathrm{mm}]$ & $301(34)$ & $234(52)$ & $0.002^{*}$ \\
\hline Y translation $[\mathrm{mm}]$ & $251(46)$ & $234(64)$ & 0.239 \\
\hline$Z$ translation $[\mathrm{mm}]$ & $110(27)$ & $225(57)$ & $0.002^{*}$ \\
\hline \hline
\end{tabular}

$*$ p-value $<0.05$ 
brace was the only device significantly reducing the neck mobility for axial rotation on the scooter $\left(\mathrm{SS}=153 \pm 20^{\circ}, \mathrm{SB}=102 \pm 28^{\circ} \quad(\mathrm{p}=0.001)\right.$ ) (Figure 5).

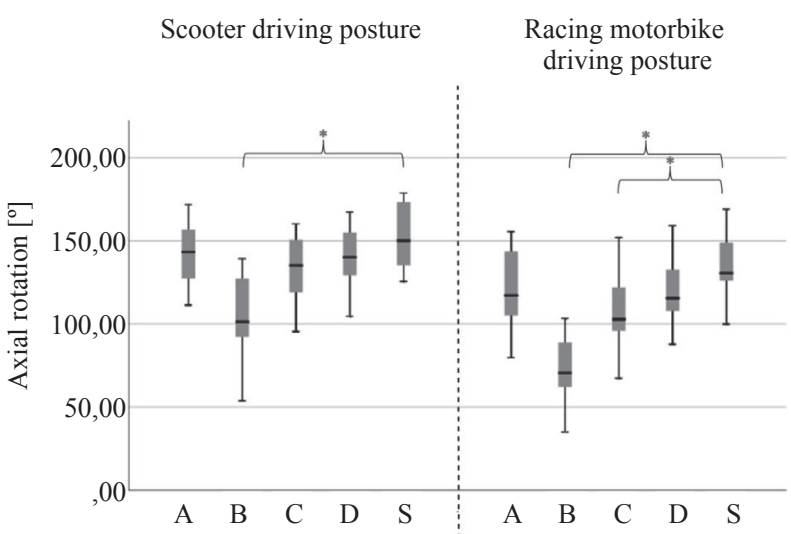

A - Alpinestar, B - EVS, C - KTM, D - Ortema, S - no neck brace

Figure 5 - Neck mobility in axial rotation for five testing conditions (Significant differences between two testing conditions are presented in brackets with a “*”.)

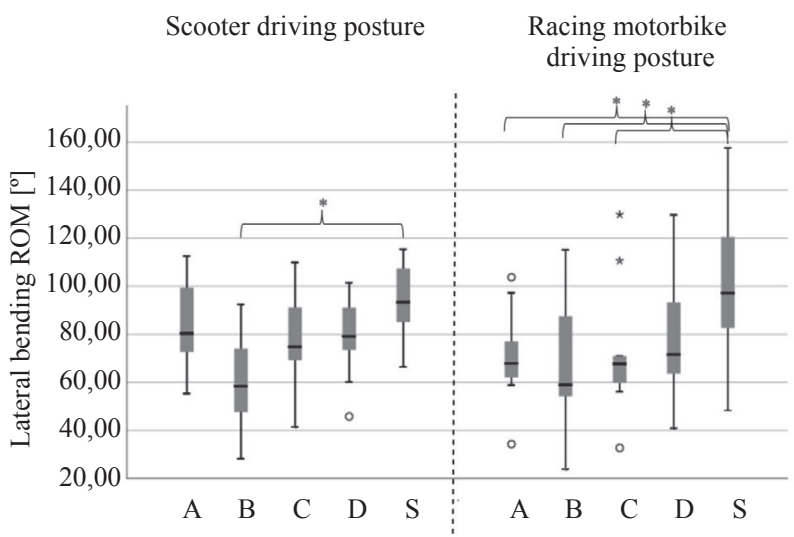

A - Alpinestar, B - EVS, C - KTM, D - Ortema, S - no neck brace

Figure 6-Neck mobility in lateral bending for five testing conditions (Significant differences between two testing conditions are presented in brackets with a “*”.)

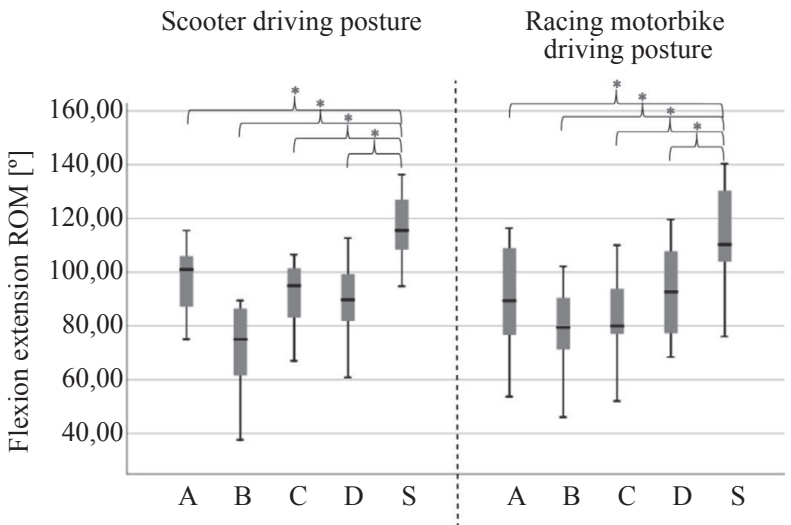

A - Alpinestar, B - EVS, C - KTM, D - Ortema, S - no neck brace

Figure 7 -Neck mobility in flexion/extension for five testing conditions(Significant differences between two testing conditions are presented in brackets with a “*”.)
EVS and KTM neck braces significantly reduced the neck mobility for axial rotation on the racing motorbike ( $\mathrm{YS}=135 \pm 21^{\circ}, \mathrm{YB}=74 \pm 20^{\circ} \quad(\mathrm{p}=0.001)$ and $\mathrm{YC}=109 \pm 23^{\circ}(\mathrm{p}=0,010)$ ) (Figure 5). No significant difference was found between the two driving postures for lateral bending physiological ROM $\left(\mathrm{SS}=94 \pm 16^{\circ}, \mathrm{YS}=100 \pm 30^{\circ}, \mathrm{p}=0.308\right)$ (Table 1$)$. The EVS neck brace was the only device significantly reducing the neck mobility for lateral bending on the scooter $\left(\mathrm{SS}=94 \pm 16^{\circ}, \mathrm{SB}=60 \pm 20^{\circ} \quad(\mathrm{p}=0.001)\right)$ (Figure 6). Alpinestar, EVS, and KTM significantly reduced the neck mobility for lateral bending on the racing motorbike ( $\mathrm{YS}=100 \pm 30^{\circ}, \mathrm{YA}=71 \pm 20^{\circ}$ $(\mathrm{p}=0.017), \mathrm{YB}=69 \pm 28^{\circ}(\mathrm{p}=0.017)$, and $\mathrm{YC}=73 \pm 27^{\circ}$ $(\mathrm{p}=0.032))$ (Figure 6$)$. All the neck braces significantly reduced the neck mobility for flexion/extension on the scooter $\left(\mathrm{SS}=117 \pm 13^{\circ}, \mathrm{SA}=98 \pm 13^{\circ}(\mathrm{p}=0.001)\right.$, $\mathrm{SB}=72 \pm 18^{\circ}(\mathrm{p}<0.001), \mathrm{SC}=92 \pm 14^{\circ}(\mathrm{p}<0.001)$ and $\left.\mathrm{SD}=90 \pm 15^{\circ}(\mathrm{p}<0.001)\right)$, and on the racing motorbike $\left(\mathrm{YS}=115 \pm 19^{\circ}, \mathrm{YA}=80 \pm 20^{\circ}(\mathrm{p}=0.01), \mathrm{YB}=79 \pm 17^{\circ}\right.$ $(\mathrm{p}<0.001), \mathrm{YC}=83 \pm 16^{\circ}(\mathrm{p}<0.001)$, and $\mathrm{YD}=93 \pm 18^{\circ}$ $(\mathrm{p}=0,012))$ (Figure 7$)$.

\subsection{Translational range of motion}

For $\mathrm{X}$ translation, the neck physiological range of motion (without neck brace) was found significantly higher $(\mathrm{p}=0.002)$ on the scooter $(301 \pm 34 \mathrm{~mm})$ than for the racing motorbike $(234 \pm 52 \mathrm{~mm})$ (Table 1). All the neck braces significantly reduced the neck mobility in $\mathrm{X}$ translation on the scooter $\quad(S S=301 \pm 34 \mathrm{~mm}, S A=260 \pm 32 \mathrm{~mm} \quad(p=0.008)$, $\mathrm{SB}=207 \pm 56 \mathrm{~mm} \quad(\mathrm{p}<0.001), \quad \mathrm{SC}=253 \pm 40 \mathrm{~mm}$ $(\mathrm{p}=0.009), \quad$ and $\quad \mathrm{SD}=234 \pm 37 \mathrm{~mm} \quad(\mathrm{p}<0.001))$ (Figure 8). EVS and KTM significantly reduced the neck mobility for $\mathrm{X}$ translation on the racing motorbike $(\mathrm{YS}=234 \pm 52 \mathrm{~mm}, \mathrm{YB}=157 \pm 41 \mathrm{~mm} \quad(\mathrm{p}=0.001)$, and $\mathrm{YC}=179 \pm 37 \mathrm{~mm} \quad(\mathrm{p}=0.011)$ ) (Figure 8). No significant difference was found for $\mathrm{Y}$ translation physiological ROM between the two driving postures $(\mathrm{SS}=251 \pm 46 \mathrm{~mm}, \mathrm{YS}=234 \pm 64 \mathrm{~mm}$, $\mathrm{p}=0.239$ ) (Table 1). The EVS neck brace was the only device significantly reducing the neck mobility in $\mathrm{Y}$ translation on the scooter $(\mathrm{SS}=251 \pm 46 \mathrm{~mm}$, $\mathrm{SB}=160 \pm 56 \mathrm{~mm}(\mathrm{p}=0.003))$ and on the racing motorbike $(\mathrm{YS}=234 \pm 64 \mathrm{~mm}, \mathrm{YB}=132 \pm 47 \mathrm{~mm}(\mathrm{p}=0.003))$ (Figure 9). For $\mathrm{Z}$ translation, the neck physiological range of motion (without neck brace) was found significantly higher $(\mathrm{p}=0.002)$ on the racing motorbike $(225 \pm 57 \mathrm{~mm})$ than for the scooter $(110 \pm 27 \mathrm{~mm})$ (Table 1). Alpinestar, EVS, and KTM significantly reduced the neck mobility in $\mathrm{Z}$ translation for 
both the scooter $(\mathrm{SS}=111 \pm 27 \mathrm{~mm}, \mathrm{SA}=77 \pm 25 \mathrm{~mm}$ $(p=0.002), \quad S B=70 \pm 32 \mathrm{~mm} \quad(p=0.003), \quad$ and $\mathrm{SC}=75 \pm 18 \mathrm{~mm}(\mathrm{p}=0.002))$ and the racing motorbike $(\mathrm{YS}=225 \pm 57 \mathrm{~mm}, \mathrm{YA}=147 \pm 51 \mathrm{~mm}(\mathrm{p}=0.002)$, $\mathrm{YB}=167 \pm 49 \mathrm{~mm} \quad(\mathrm{p}=0.011)$, and $\mathrm{YC}=147 \pm 41 \mathrm{~mm}$ $(\mathrm{p}=0.001))($ Figure 10).

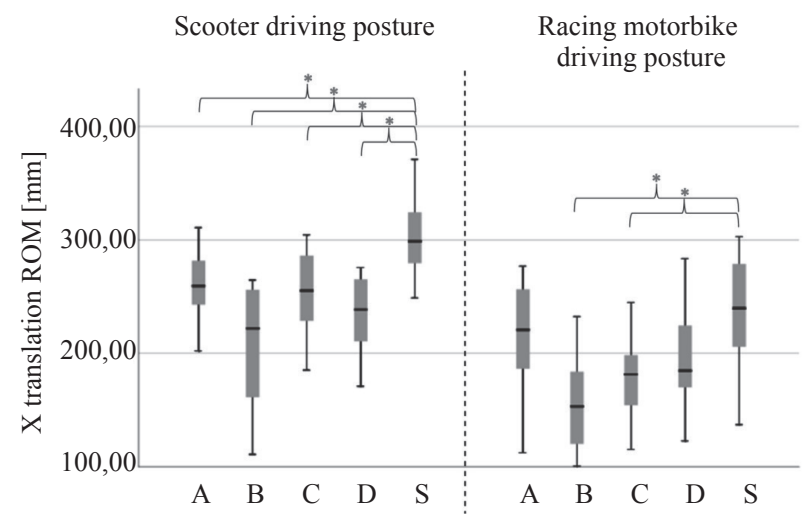

A - Alpinestar, B - EVS, C - KTM, D - Ortema, S - no neck brace Figure 8 - Neck mobility in X translation for five testing conditions (Significant differences between two testing conditions are presented in brackets with a “*”.)

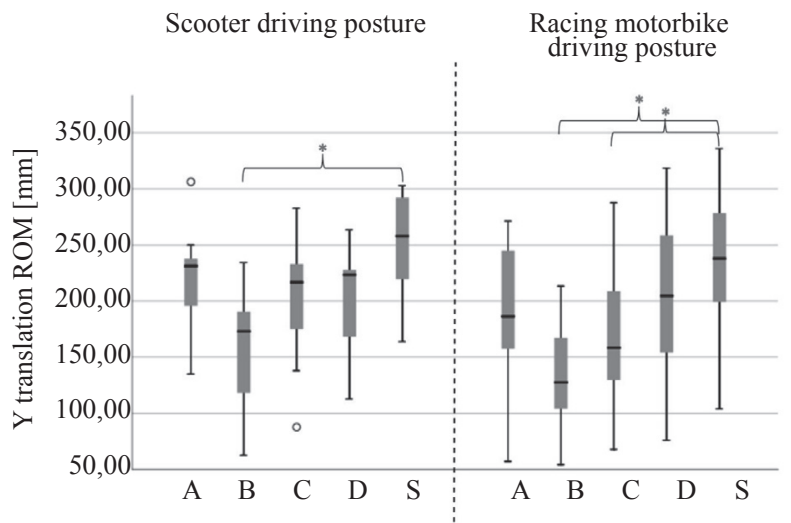

A - Alpinestar, B - EVS, C - KTM, D - Ortema, S - no neck brace

Figure 9-Neck mobility in Y translation for five testing conditions (Significant differences between two testing conditions are presented in brackets with a “*”.)

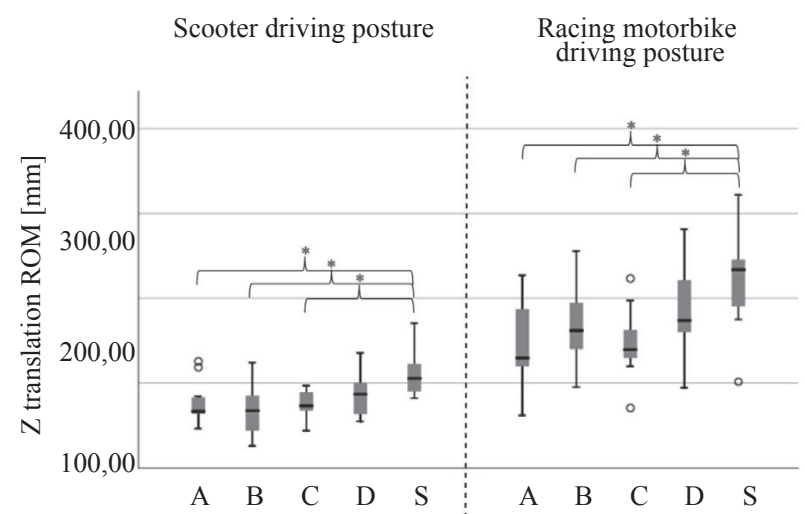

A - Alpinestar, B - EVS, C - KTM, D'- Ortema, S - no neck brace

Figure 10-Neck mobility in Z translation for five testing conditions (Significant differences between two testing conditions are presented in brackets with a “*”.)

\section{DISCUSSION}

This work provides a novel understanding of the capacity of the neck brace to reduce, in quasi-static loading conditions, the neck mobility and keep it under its physiological range of motion, depending on the driving postures associated with the PTW type. Four neck braces were tested by volunteer subjects on two different PTWs (a scooter and a racing motorbike). An optoelectronic motion capture system and a novel measurement method were used in this study because of the complexity of cervical spine injury mechanisms and the large variability of loading conditions on the head-neck components during motorcyclist accidents [28]. It allowed considering combinations of rotational and translational neck movements for assessing neck brace restrictions.

The neck braces tested in this study reduced the neck mobility differently. Flexion/extension was the only movement significantly reduced by all the braces regardless of the driving posture. Caudo-cranial translations associated with compressive movements of the cervical spine were also significantly reduced by 3 out of the 4 neck braces regardless of the driving posture. The significant reduction of neck mobility for the caudo-cranial translation and flexion/extension combination observed for 3 of the neck braces showed their protective potential for frontal and rear impacts that are frequently coupled with compressive movements [29]. Neck mobility in axial rotation, involving shear stresses in the cervical spine, was significantly reduced by only one neck brace on the scooter and two neck braces on the racing motorbike. A reduction of neck mobility in lateral bending was significant for only one neck brace on the scooter and three neck braces on the racing motorbike. These results highlight the important effect of driving posture on the protective potential of neck braces against lateral impacts. These different neck mobility reduction mechanisms between neck braces could partly be explained by the different components of their design, such as shell stiffness or thickness, or the configuration of foam layers. For example, the EVS neck braces, which were the only ones with a thick foam layer (approximately $30 \mathrm{~mm}$ ), were shown to significantly restrain neck mobility for all movements. In that case, the thick foam layer seems to reduce the gap between the helmet and the neck brace, leading to early contact during movement. This could explain the difference of restriction between the EVS neck brace and the three others for axial rotation and 
lateral bending movements on the scooter. Given the potential importance of the neck brace design on neck mobility reduction, further studies should investigate the effect of different design parameters with respect to changes in neck mobility.

Although some studies have investigated motorcyclist driving postures [24, 26], none have focused on postural differences between two types of PTW, such as a scooter and a racing motorbike. Our results show that the driving posture significantly affects the neck mobility in axial rotation, as well as in postero-anterior and caudo-cranial translations. A scooter allows larger ROM in axial rotation and postero-anterior translation, whereas caudo-cranial translation is larger on a racing motorbike. The discrepancies in translational reduction associated with the driving posture could be explained by the very different initial angles between the motorcyclist's head and thorax, which affect the natural lordosis of the cervical spine. Actually, racing motorbike drivers naturally adopt a posture with the neck in extension, reducing the remaining ROM. This finding shows the importance of taking into account the driving posture when assessing the effectiveness of the neck brace.

Although providing valuable insights into the ability of neck braces to reduce the cervical spine mobility and keep it under the physiological range of motion, as well as the influence of the driving posture, this study has some limitations. First, the use of a larger sample size of volunteer subjects would allow discriminating the effect of morphological variability, age, and gender, in addition to posture and neck brace designs. Second, the experiment focused on mobility measurements for pure movements in quasi-static conditions corresponding to flexion/extension, lateral bending, and axial rotation. However, cervical spine injuries result from a dynamic impact to the motorcyclist's helmet during an accident potentially involving combined movements of the head [28]. Consequently, further studies should also investigate the neck mobility, including dynamic and combined movements such as flexion and axial rotation, for example. Third, we are aware that helmet design could have an influence on the final ROM results. However, in order to avoid this factor when assessing the effect of neck brace designs, we decided not to take it into account, focusing instead on one helmet model (SHARK, S800, size L). Further work may investigate the effect of helmet models, sizes, and shapes on head movement restriction. Finally, as this work did not focus on the effect of such devices on neck ROM for driving safety, additional investigations are needed. In particular, the ROM required for driver safety while wearing a neck brace may be performed in controlled driving environments, such as in driving simulators, to further address the compromise between injury prevention and driving safety.

\section{CONCLUSION}

This work aimed to evaluate the ability of neck braces to reduce neck mobility and to keep it under the physiological range of motion, depending on driving postures induced by different PTWs. Although the tested neck braces are designed for preventing cervical spine injuries, this study showed that they do not apply movement restrictions in the same manner, except for neck mobility in flexion/ extension. This underscores the need to take into account the multi-directional loading of the cervical spine involved in PTW accidents. Moreover, the effects of different design parameters with respect to changes in neck mobility needs to be further investigated. Furthermore, results of this study show that the driving posture has a significant impact on neck mobility for three specific movements: axial rotation, postero-anterior translation, and caudo-cranial translation. This suggests that neck brace protection effectiveness should be evaluated while taking the PTW type into account. The ability of the neck brace to reduce neck mobility and keep it under the injurious ROM level still needs to be further investigated in dynamic test conditions. However, this work represents a first step toward the improvement of the neck brace device evaluation process by taking into account the ability of the brace to reduce the cervical spine range of motion and keep it under physiological limits for various postures.

\section{ACKNOWLEDGMENT}

The authors would like to thank all volunteer subjects as well as Morgane Evin who helped to conduct this study successfully.

BRIEG LECOUBLET ${ }^{1,2,3,4}$

E-mail: brieg.lecoublet@gmail.com

YVAN PETIT, Ph.D. 2,3,4

E-mail: yvan.petit@etsmtl.ca

ERIC WAGNAC, Ph.D. 2, 3,4

E-mail: eric.wagnac@etsmtl.ca 


\section{DOMINIC BOISCLAIR ${ }^{1,2}$}

E-mail: dominicboisclair@hotmail.com

PIERRE-JEAN ARNOUX, Ph.D. ${ }^{1,2}$

E-mail: pierre-jean.arnoux@univ-eiffel.fr

${ }^{1}$ Aix Marseille Université, Université Gustave Eiffel, LBA

Boulevard Pierre Dramard, 13015 Marseille, France

2 iLab-Spine - Laboratoire international en imagerie et biomécanique du Rachis

5400 Boulevard Gouin O, Montréal,

QC H4J 1C5, Canada

${ }^{3}$ Departement d'ingénierie Mécanique

École de technologie supérieure

1100 Rue Notre-Dame Ouest, Montréal,

QC H3C 1K3, Canada

${ }^{4}$ Centre de recherche, Hôpital Sacré Coeur de Montréal 5400 Boul Gouin O, Montréal, QC H4J 1C5, Canada

\section{LES COLLIERS CERVICAUX ET LA POSTURE DE CONDUITE AFFECTENT LA MOBILITE DU COU SUR LES DEUX ROUES MOTORISES}

\section{RÉSUMÉ}

Les lésions au rachis cervical sont très répandues chez les motocyclistes lors d'accidents de la route ou en compétitions. Les colliers cervicaux sont conçus pour réduire les lésions au rachis cervical lors des accidents en réduisant la mobilité articulaire du cou et en la gardant à l'intérieur du seuil physiologique. Ce travail a pour objectif d'évaluer la capacité des colliers cervicaux à réduire la mobilité du cou du motocycliste selon deux postures de conduite associées aux types de deux-roues motorisés utilisés. La mobilité articulaire du coup de douze sujets volontaires testant quatre colliers cervicaux sur deux types de deux-roues motorisés (Scooter et moto de course) est mesurée grâce à l'utilisation d'un dispositif de capture de mouvements optoélectronique. Avec les dispositifs testés, la mobilité articulaire est significativement réduite par rapport aux amplitudes physiologiques dans toutes les directions. Cependant, la flexion/extension est l'unique mouvement réduit par l'ensemble des colliers cervicaux testés. Ceci suggère que ce type de dispositif ne semble pas protéger le rachis cervical pour toutes les directions d'impact pouvant apparaitre lors d'un traumatisme. Par ailleurs, les deux types de deux roues motorisés considérés dans cette étude affectent significativement la mobilité $d u$ cou en rotation axiale ainsi que pour les translations antéro-postérieure et caudo-crâniale. Ceci met en avant également l'importance de la prise en compte de la posture de conduite lors de l'évaluation des colliers cervicaux.

\section{MOTS CLÉFS}

Motocyclistes; Deux roues motorisés, Collier cervical, Rachis cervical, Mobilité du cou, Posture de conduite.

\section{REFERENCES}

[1] ONISR. La sécurité routière en France - Bilan de l'accidentalité de l'année 2017; 2017.

[2] NHTSA. Traffic Safety Facts-2017 data (DOT HS 812 785). Wash. DC NHTSA's Natl. Cent. Stat. Anal; 2017.

[3] Ankarath S, Giannoudis PV, Barlow I, Bellamy M, Matthews S, Smith R. Injury patterns associated with mortality following motorcycle crashes. Injury. 2002;33(6): 473-477. DOI: 10.1016/S0020-1383(02)00048-7

[4] Robertson A, Branfoot T, Barlow IF, Giannoudis PV. Spinal injury patterns resulting from car and motorcycle accidents. Spine Phila Pa 1976. 2002;27(24): 2825-30.

[5] Kemper AR, McNally C, Duma SM. The influence of strain rate on the compressive stiffness properties of human lumbar intervertebral discs. Biomed. Sci. Instrum. 2006;43: 176-181.

[6] Crowell RR, Shea M, Edwards WT, Clothiaux PL, White AA $3^{\text {rd }}$, Hayes WC. Cervical injuries under flexion and compression loading. J Spinal Disord. 1993;6(2): 175-81.

[7] Cusick JF, Yoganandan N. Biomechanics of the cervical spine 4: major injuries. Clin. Biomech. 2002;17(1): 1-20.

[8] Nightingale RW, Bass CR, Myers BS. On the relative importance of bending and compression in cervical spine bilateral facet dislocation. Clin. Biomech. 2019 Apr;64: 90-97. DOI: 10.1016/j.clinbiomech.2018.02.015

[9] Nightingale RW, Camacho DL, Armstrong AJ, Robinette JJ, Myers BS. Inertial properties and loading rates affect buckling modes and injury mechanisms in the cervical spine. J. Biomech. 2000;33(2): 191-197. DOI: 10.1016/ s0021-9290(99)00156-6

[10] Pintar FA, Yoganandan N, Voo L. Effect of age and loading rate on human cervical spine injury threshold. Spine Phila Pa 1976. 1998;23(18): 1957-62.

[11] Chinn C et al. COST 327 Motorcycle Safety Helmets; 2001.

[12] Amiri M, Jull G, Bullock-Saxton J. Measuring range of active cervical rotation in a position of full head flexion using the 3D Fastrak measurement system: An intra-tester reliability study. Man Ther. 2003;8(3): 176-9. DOI: 10.1016/s1356-689x(03)00009-2

[13] Audette I, Dumas JP, Cote JN, De Serres SJ. Validity and between-day reliability of the cervical range of motion (CROM) device. J Orthop Sports Phys Ther. 2010;40(5): 318-23. DOI: 10.2519/jospt.2010.3180

[14] Hall T, Robinson K. The flexion-rotation test and active cervical mobility - A comparative measurement study in cervicogenic headache. Man. Ther. 2004;9(4): 197-202. DOI: 10.1016/j.math.2004.04.004

[15] Tousignant M, Smeesters C, Breton AM, Breton E, Corriveau $\mathrm{H}$. Criterion validity study of the cervical range of motion (CROM) device for rotational range of motion on healthy adults. J Orthop Sports Phys Ther. 2006;36(4): 242-8. DOI: 10.2519/jospt.2006.36.4.242

[16] Williams MA, Williamson E, Gates S, Cooke MW. Reproducibility of the cervical range of motion (CROM) device for individuals with sub-acute whiplash associated disorders. Eur Spine J. 2012;21(5):872-8. DOI: 10.1007/s00586-011-2096-8

[17] Yoo WG, Park SY, Lee MR. Relationship between active cervical range of motion and flexion-relaxation 
ratio in asymptomatic computer workers. $J$ Physiol Anthr. 2011;30(5): 203-7. DOI: 10.2114/jpa2.30.203

[18] Sánchez MB, Loram I, Darby J, Holmes P, Butler PB. A video based method to quantify posture of the head and trunk in sitting. Gait Posture. 2017;51: 181-187. DOI: 10.1016/j.gaitpost.2016.10.012

[19] Lecoublet B, Boisclair D, Evin M, Wagnac E, Petit Y, Aubin C-E, Arnoux P-J. Assessing the Global Range of Motion of the Helmeted Head Through Rotational and Translational Measurements. Int. J. Crashworthiness. 2019; 321-7. DOI: 10.1080/13588265.2019.1593288

[20] Leatt C, De Jongh C, Keevy PA. White paper: Research and development efforts towards the production of the Leatt Brace Moto GPS unrestrained torso neck brace. South Africa: Cape Town; 2012.

[21] Khosroshahi S, Ghajari M, Galvanetto U. Assessment of the protective performance of neck braces for motorcycle riders: A finite-element study. Int. J. Crashworthiness. 2018; 487-498. DOI: 10.1080/13588265.2018.1478937

[22] Meyer F, Deck C, Willinger R. Protection from motorcycle neck braces using FE modelling. Sports Engineering. 2018;21: 267-276. DOI:10.1007/s12283-018-0268-z

[23] Kamergam K, Sapuan SM, Ismail MY, Bahri M, Seetha P. Motorcyclist's Riding Discomfort in Malaysia: Comparison of BMI, Riding Experience, Riding Duration and
Riding Posture. Human Factors and Ergonomics in Manufacturing and Service Industries. 2011;23(4): 267-278. DOI:10.1002/hfm.20317

[24] Amrutkar AS, Rajhans NR. Ergonomic posture for motorcycle riding. Conference paper. 2011.

[25] Ospina Mateus H, Quintana AL. Understanding the impact of physical fatigue and postural comfort in the driving of motorcycles: A systematic review. Journal of Transport \& Health. 2019;12: 290-318. DOI:10.1016/j. jth.2019.02.003

[26] Robertson SA, Minter A. A study of some anthropometric characteristics of motorcycle riders. Applied Ergonomics. 1996;27(4): 223-229. DOI: 10.1016/00036870(96)00007-5

[27] Barone S, Curcio A. A computer-aided design-based system for posture analyses of motorcycles. $J$. Eng. Des. 2004;15(6): 581-595. DOI: 10.1080/ 09544820410001731146

[28] Chinn B, Canaple B, Derler S, et al. COST 327 Motorcycle Safety Helmets. European Co-Operation in the Field of Scientific and Technical Research; 2001.

[29] Ooi SS, Wong SV, Radin Umar RS, Azhar AA, Megat Ahmad MMH. Cervical spine injuries sustained by motorcyclists in road crashes in Malaysia. Int. J. Crashworthiness. 2005;10(3): 295-303. DOI: 10.1533/ijcr.2005.0348 